\title{
TOLSTOY Y SU OBRA
}

Pocos homenajes tan legítimos como el que el mundo entero ha tributado a Tolstoy con motivo de su centenario. Por la profundidad con que supo sondear la conciencia humana en la hora que le tocó vivir y sus sueños de paz y de amor fraternal entre los hombres; por su redentorismo cristiano y su consagración a la causa de la justicia; por el arte maravilloso de su obra inmensa y sobre todo por su vida, que es la más grande y noble de sus obras; Tolstoy es uno de los más hermosos genios que han honrado a la humanidad.

Jamás producción alguna estuyo más íntimamente ligada a una vida, ni nunca se dió una adecuación más exacta entre el escritor y el hombre. Como Goethe - $y$ tal vez; con más razón que Goethe,- Tolstoy pudo llamar a su obra "fos fragmentos de una gran confesión".

No hay relato del Jutane nowelistaeglie nonacuseoun hecho real de su existencia o que por lo menos no se halle ya en germen en una impresión vivida. Sus mejores tipos son o él mismo - reproducido hasta lo infinito - o recuerdos de familia o imágenes queridas de camaradas y amigos. Cuando contemplamos la galería de estos retratos inmortales, cómo no extasiarnos ante la dulce y tierna princesa María, en quien recuerda a su madre, con una sonrisa siempre franca para consolar a los desgraciados y una mano siempre pronta para socorrer a los pobres; el príncipe Andrés, retrato del mismo novelista, sumido primero en la disipación, después presa de horribles remordimientos, cayendo bravamente en el campo de batalla para despertar en un hospital de sangre, curado el espíritu de toda ambición mundana; el viejo príncipe Bolkons$\mathrm{ki}$, imagen de su padre, magnífico, soberbio, grande en su misma decadencia moral y física, abrumado bajo el peso de la tradición y de los prejuicios aristocráticos; Pedro Besukhov, que es Tolstoy buscando su camino; la inolvidable pareja de Levin y Kitty, el escritor y su mujer en la época de sus amores y de su matrimonio; el imponente tipo de $\mathrm{Ne}$ kludov, que con Levin representa al hombre de la crisis moral y de la conversión; en fin, las dulces y adorables siluetas de Natacha, Sonia y 
Katiucha, los mejores recuerdos de amor y poesía que le dejó su juventud.

Hasta los personajes históricos participan de su propia vida. La galería histórica de Tolstoy es también riquísima. Figuran en ella Francismo II, el zar Alejandro, Napoleón, Kutuzov, Bagration, Separnzki, Rotopchine. El procedimiento por el cual Tolstoy introduce la historia en su novela muestra claramente hasta qué punto el escritor "creaba" el personaje histórico con elernentos de su propia personalidad. El personaje histórico es siempre visto por un personaje imaginario: el príncipe Andrés ve a Napoleón, Nicolás Rostov a Alejandro, Pedro Besukhov a Rostopchine. En la misma forma incorpora a su vida el acontecimiento histórico: Andrés Bolkonski vive la batalla de Austerlitz, Nicolás Rostov la revista de Tilsitt, Pedro Besukhov la batalla de Borodino y el incendio de Moscú.

Está tan mezclada su existencia a su obra, que ésta puede seguirse a través de su vida. Infancia, Adolescencia y Juventud son sus primeros pasos en la vida y el recuerdo de su iniciación en las letras. Con estos libros podemos seguir a Tolstoy en sus estudios de Kazan que él llama "el deierto de su adolescencia" ; en la Oniversidad, más tarde, donde estudia derecho, comenta a Rousseau y emprende un trabajo comparativo sobre el Espíritu de las Leyes y las leyes de Catalina II; en su regreso a Iasnaia Poliana, donde se interesa en la vida miserable de los mujiks; y, por último, en su viaje a Moscú, ciudad en que se entrega a la vida disipada de la juventud elegante.

Para arrancarlo del desorden de esta existencia, su hermano $\mathrm{Ni}$ -

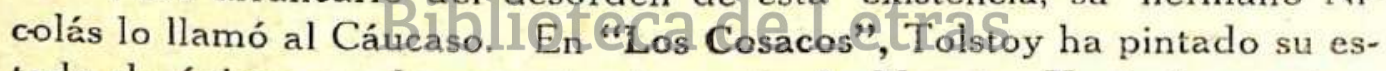
tado de ánimo en el momephtocdènpartíc den Moscó.» Tenía la conciencia de sus pasados errores y el presentimiento de que su salida para el Cáucaso iniciaba una nueva vida. Tomó parte ahí en todas las acciones militares de la campaña, lo que lo puso en condiciones de esiudiar los detalles de la vida militar; y la belleza de la naturaleza salvaje produjo en su espíritu una influencia calmante.

Durante la guerra de Oriente, Tolstoy pasó al ejército del Danubio, como agregado al Estado Mayor, y asistió al sitio de Sebastopol, donde su bravura lo hizo figurar entre los héroes de aquella acción. Los Cosacos había sido la obra pintoresca del Cáucaso; Los Recuerdos de Sebastopol fué el drama sangriento de la guerra. El Cáucaso reveló a Tolstoy la naturaleza; Sebastopol, la grandeza del sufrimiento huma-
no.

De Sebastopol pasó a San Petersburgo. Su nombre era ya una reputación rusa. Los salones se abrieron a su paso y entró en relación con los más grandes escritores de su patria. Sin embargo en medio de sus éxitos, el anhelo de una vida más pura y más noble iba surgiendo lentamente en su espíritu. "Yo y los escritores que conocí entonces, dirá más tarde en Mi Confesión, estábamos convencidos de que a noso- 
irns nos tocaba la parte principal en el progreso, de que nos pertenecía la influencia preponderante. Pensábamos que debíamos hablar sin cesar, escribir o imprimir todo lo que fuera posible. Creíamos que todo eso era necesario para la salud de la humanidad. Me imaginaba ingenuamente que yo al menos era poeta, artista, y que podía enseñar a todos, sin preguntarme siquiera si sabía lo que quería enseñar. En mi trato con los hombres contraje un nuevo vicio: el orgullo, un orgullo que se hacía cada vez más morboso, la loca seguridad de ser superior a los otros. Escribía por vanidad, por concupiscencia, por orgullo, y conformaba'mi vida a mis escritos. Para obtener la gloria y el dinero era necesario esconder el bien y mostrar el mal. Cuántas veces me ingenié para ocultar en mis escritos bajo la forma de ironía mis propias aspiraciones al bien. Pero era el éxito, y se me alababa. Además se me pagaba bien por todo aquello. Y tenía mesa magnífica, alojamiento, mujeres, sociedad. Y tenía la gloria. Mi fe en la importancia de la poesía y del desenvolvimiento intelectual era mi religión, y yo me consideraba como uno de sus sacerdotes. Era muy agradable y muy conveniente. Y yo viví bastante tiempo en esta creencia sin dudar absolutamente de su verdad".

Luego viaja por Suiza, Alemania y Francia. El esplandor de la vida europea afirmaba ya su fe en el progreso, tan cara a los enciclopedistas, cuando una ejecución capital, hecha en nombre de la justicia, durante su permanencia en París bastó para mostrarle la fragilidad de ese postulado de la civilización occidental. "Cuando ví la cabeza desprenderse del tronco y rodar por el suelo, comprendi que ninguna teoría del progreso podría fustificar jamás una iniquidad semejante. Por más que los hombres quieran' glemostainquei estenqaetigo, es saludable y necesario, nuestro corazón lo rechazará siempre con repugnancia y horror".

Decepcionado de Europa, volvió a Yasnaia Poliana. En sus tierras se consagró otra vez a remediar la miseria de los campesinos. Su acercamiento al pueblo era una manera de ir a lo primitivo como una reacción contra la sociedad y el progreso. Fundó una escuela para paisanos, y desde entonces comienzan sus estudios pedagógicos y sus trabajos de educador. Rousseau vuelve a obsesionarlo y lo medita profundamente. Ante todo debía resolver el primer problema que le planteaba su sistema pedagógico: la oposición entre la enseñanza tradicional y la negación del progreso. Influído por Rousseau sienta el principio de que la educación en vez de llevar al hombre a la civilización, debe conducirlo a la naturaleza, y que es en la naturaleza y dentro de la vida de naturaleza que debe formarse la sociedad futura. Modelar almas primitivas dentro de un ambiente primitivo era toda su ambición de educador.

Con Rousseau, Tolstoy creía que el hombre es bueno y que la sociedad lo deforma. En consecuencia era necesario desenvolver los im- 
pulsos puros del niño lejos de toda contaminación social. La escuela modelo, fundada por Tolstoy, estaba en pleno campo y era gratuita. Su regimen era el de la más absoluta libertad: los niños podían asistir a ella cuando quisieran, estudiar o no según su voluntad y no escuchar al maestro si así se sentían mejor en la escuela. Parte principal de su programa eran los paseos y excursiones. En plena libertad, al aire libre, el maestro establecía nuevas relaciones con sus discípulos en que reinaban la más completa intimidad y la más absoluta franqueza. "El niño paisano, escribía Tolstoy por entonces, no siente el frío que le muerde por las desgarraduras de sus ropas, pero los problemas nuevos, las dudas, le atormentan. A trabajar, aprenderá más tarde, como ha aprendido a respirar. El niño tiene necesidad de saber a dónde conduce nuestra vida. Vosotros habéis tenido tiempo de buscar, de pensar, de sufrir; dadle el resultado de vuestros sufrimientos: eso sólo es lo que necesita".

Al mismo tiempo fundaba una revista pedagógica con el título de Yasnaia Poliana, donde mostraba los resultados amargos de la civilización europea, que no eran en suma sino la explotación del pueblo en provecho de las clases privilegiadas; y componía su Abecedario, del que extrajo más tarde el grupo de lecturas selectas que lleva por título Los Cuatro Libros de Lectura, célebre hoy como obra literaria, y el mejor libro que puede ponerse actualmente en manos de la juventud.

La desaparición de su hermano Nicolás lo afectó profundamente. Por primera vez, la miưrtiedo hera decerca ýlen yna persona tan querida. Nicolás fué el mejor $y$ tal vez ehúnico amigo de Tolstoy. Este hecho tuvo una influencra decisiva en su vida. La muerte es desde entonces uno de sus temas favoritos de meditación; se convierte en la única verdad positiva; ante ella el corazón se muestra puro y desnudo, y caen todos los velos que cubren las mentiras o hipocresías sociales. En busca de soledad y de paz, lo abandona todo y parte para el desierto, hacia los Baschkirs, donde pensaba respirar más libremente y "vivir la vida animal".

De regreso, en 1862, a los treinta y cuatro años, casó con Sofía de su vida interior. En ese período de calma espiritual y de paz hogareña, Tolstoy escribe Guerra y Paz. Esta obra abre la era gloriosa de sus grandes triunfos. Hasta entonces, el novelista era una reputación rusa, con Guerra y Paz va a ser una reputación europea y después uni-
versal.

Escribía Ana Karenine cuando le saltó bruscamente el problema del por qué de la vida. Es el comienzo de su crisis moral. Levin y lista presenta a Levin con sus mismas dudas y sus mismas inquietudes. ¿Qué hacer? se pregunta, y esta pregunta que es una interrogación 
abierta sobre su espíritu y el espíritu de los demás, es el título de una obra posterior. Más tarde, en Mi Confesión contará las tribulaciones de esta crísis y la alegría de su conversión.

Ante el malestar social, ante la corrupción general, ante la mentira y la hipocresía que todo lo invadía, Tolstoy se encontraba desarmado. Su revolución era una revolución sin revolución, porque estaba inspirada en su principio de la no resistencia al mal por la violencia; su acción social era una acción sin acción desde que reposaba en la idea del abandono absoluto a la voluntad de Dios, que había predicado; fidelidad al destino y a la fatalidad cuya raíz hay q' buscarla en el fondo asiático del pueblo ruso.

Por todas partes ve Tolstoy el mal, el vacío, la nada; las instituciones sociales fundadas sobre la mentira y el fraude, la ciencia convertida en una superchería, la religión deformada por la teología, la intransigencia y la intolerancia. El mundo lo asfixiaba, y sentía la necesidad de huír, pero no sabía ni adónde ni cómo. Tolstoy era semejante a un hombre extraviado en una selva, que corre en todos los sentidos sin poder detenerse, aun sabiendo que cada paso que da lo aleja más de su ruta. Al borde del abismo, una fuerza invencible lo llevaba a desembarazarse de la vida. En páginas admirables ha contado cómo a veces tenía que ocultarse él mismo los instrumentos con los cuales podía atentar contra su propia existencia.

La salud le vino del pueblo. Un día un mujik con el cual conversaba, le dijo: "Nosotros no vivimos para nosotros sino para Dios". Advirtió entonces que lós cåmpesinos têníañ un-sentido de la vida, y que este sentido lo adquirian no por la razón sino por la fe; que creían en Dios y no lo razonaban; que GivianlidesusVmanos y habían suprimido la explotación; que aceptaban las cargas de las clases altas resignadamente y $\sin$ hacer uso de la fuerza. Comprendió que los campesinos labraban su vida como algo independiente de su pobre personalidad individual, en virtud del amor. Nuestra carne es perecedera; pero esta vida tallada en el amor y para el amor, como una obra de arte, que se puede ofrecer a los demás y legar a la posteridad, es inmortal. "La única vida digna de ser vivida, según Tolstoy, consistirá en vivir de manera que la muerte no pueda aniquilar la vida".

Tolstoy advierte una oposición irreductible entre la razón y la fe. Y el sentido de la vida había que buscarlo en una ú otra. La razón es lo abstracto, lo inerte, lo artificial, la ciencia, la religión teológica, la escolástica; la fe, el impulso primitivo y puro, instinto de adivinación, destello de la verdad dvina, la luz. "La razón, dice, no me ha enseñado nada; todo lo que sé me ha sido enseñado por el corazón, y el corazón es la fe".

Desde entonces adopta la fe como único guía de su espíritu. Tolstoy camina hacia la conversión. "Hay una verdad, exclama. Y hay que buscarla aun en la ilusión de la bóveda celeste y en el movimiento 
aparente de los astros". Porque la fe es la vida, aun más la fuerza de la vida: impulso y dirección, a la vez espíritu que anima y brújula que guía. "Las respuestas dadas por la fe a la esfinge de la vida contienen la sabiduría más profunda de la humanidad.

Pero la fe de Tolstoy es una acción: sólo tiene valor en cuanto es vivida. La fe inerte, pasiva, es un lujo más de los hombres cómodamente instalados en la vida, la fe del fariseo, una consolación epicúrea y egoista. Tolstoy rechaza enérgicamente esta fe que proclama falsa y estéril. Para él la verdadera fe es la de los hombres simples, de aquellos que ponen de acuerdo su vida con la verdad.

Un día la salud completa le vino. "Una tarde de primavera prècoz, cuenta, estaba solo en el bosque. Súbitamente sentí que no vivía sino cuando creía en Dios. A su solo pensamiento las ondas gozosas de la vida se levantaban en mí. Todo se animaba en torno mío: todo recibía un sentido. Entonces ¿qué es lo que busco ya - me dije-, si lo tengo? Conocer a Dios es vivir. ¡Dios es la vida!" Estaba salvado. Dios se le había aparecido. Era su conversión.

Necesitaba, ahora que conocía a Djos, ver si podía instalarle dentro del marco de su religión ortodoxa. La revisó escrupulosamente; es-
tudió sus prina tudió sus principios y sus dogmas. Pero encontró que era imposible. No fueron, sin embargo los dogmas y los principios lo que lo apartaba más
de la iglesia, la intolerancia sino las cuestiones de carácter práctico. Dos sobre todo: ta dada al homicidio y mutua de las iglesias y la sanción formal o táciEra necesario con, la guerra y la pena de muerte.

de Cristo sobre la fe y

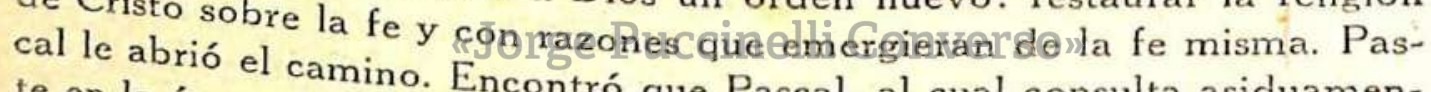
te en la época de su conversión, había Pascal, al cual consulta asiduamenzones, que la razón no consión, había dicho: "El corazón tiene sus raes la razón de nuestra existencia, es el amor; y el reino de Dios, el reino
del amor.

Para Tolstoy esta religión del amor es la que profesa el pueblo hu-
milde e ignorante, que vive plotación del hombre pore del trabajo de sus manos y no conoce la exviolencia a la violencia, el hombre, que no opone el mal al mal ni la luntad de Dios. Es la, que se orienta por la fe y se abandona a la voda solamente en los. Es doctrina de Cristo, cuya sabiduría está conteniA tal aspiracion. Evangelios.

todos los ideales de orden perfeccionamiento moral deben subordinarse de conducta a los que orden más inmediato. Tolstoy propone una regla dicar el camino a quien quieran seguirle. "Hay, dice, dos medios de inhacia el árbol, desde aquel busca. El primero consiste en decir: Vé la orilla del río- hacia el árbol hacia la aldea, desde la aldea - por dirección a quien busca el túmulo, etc. El otro consiste en indicar la zable; o una estrella te ind camino: Vé hacia el Este, el sol inalcanza indicará siempre la dirección. El primero es el 
de las normas religiosas, superficiales y temporales; el segundo es el de la conciencia interior de una verdad eterna e inmutable: una meta supreina e inaccesible No da ninguna indicación de acto. Es la doctrina de $C_{r}$ isto. Los fariseos quedaban satisfechos con halier cumplido. Para el cristianismo cada grado de perfección provoca el deseo de subir más ari ha. Eì cristianismo, como el Publicaisu, se reconoce siempre imperfecio. El hombre que confiesa la ley del acto (ai fariseo) es como aquel cue se encuentra dentro del círsulo alunibrado de una linterna fija y no tiene cómo seguir adelante. El que confiesa la doctrina de la meta es semejante a aquel que lleva delante de si misinu un foco: la luz va siempre ante él, lo estimula a seguir su ruta y le descubre de continuo nuevos espacios iluminados que le atraen".

En 1900 la influencia de Tolstoy en Rusia era enorme. La ola revolucionaria, que había contribuído a levantar, anunciaba ya la tormenta que pronto debía desencadenarse. Después de los intelectuales, hubía ganado al pueblo; y por esta época, sus legionarios, venidos a Yasnaia Poliana, desfilaban amenazadores debajo de sus ventanas.

Sin embargo, sus últimos años fueron profundamente amargos. La resistencia tenaz que los suyos opusieron a su proyecto de repartir sus bienes entre los campesinos, le impedía poner su vida de acuerdo con su doctrina. Por todas partes vola la inutilidad de sus esfuerzos para conducir a los hombres hacia el reino de amor que había soñado. Hasta su principio de la no resistencia al mal comenzaba a hacer crisis en su espíritu. Diariamente recibía cartas de sus adeptos protestando contra aquel principio que ataba sés manos y los reducía a la impotencia. Decíanle que a todo el mal que la clase dominante hacía al pueblo, sólo podría respondersè goñ dá Qenganza y la grara.

Era muy triste para un hombre gue había vivido esperando el reino de la paz y del amor tener que cerrar los ojos ante esas visiones de desolación y de sangre.

Negado por sus mismos discípulos, condenado a la deportación, excomulgado por el Santo Sínodo, amenazado por el Poder, atormentado por los mudos reproches de sus amigos, devorado por la fiebre, presa de intensa desesperación, y casi moribundo, abandona su casa y a los suyos y, fugitivo, marcha clurante varios días por caminos cubiertos de nieve hasta llegar a un monasterio que le abre sus puertas y le proporciona asilo. Pocos días después, muere en brazos de su hija Alejandra que había logrado alcanzarlo en su refugio.

Cuando contemplamos la figura de Tolstoy, en su vida y en la íniegra totalidad de su obra, lo que primero excita nuestra admiración es la amplitud desconcertante de su genio. Filósofo, poeta, novelista, dra- 
maturgo, pedagogo, sociólogo, moralista, esteta, lo fué todo, y en todo dejó impresas las huellas de su meditación y de su análisis.

Pero lo que hay en él de especificamente sustancial y orgánico es el pensador. No es, sin embargo, el filósofo de la abstracción metafís:ca. Su filosofía lo conduce a la moral, porque para Tolstoy la suprema verclad es el bien, y la sabiduría del bien la única sabiduría posible. Por esto, toda su obra está inspirada en un ideal de perfeccionamiento moral. Para trabajar por él, el filósofo se convierte en apóstol, y el apóstol en fustigador implacable de todos los vicios y preocupaciones de su pueblo y de su época. Su bbra entera es por esta razón la crítica social más penetrante y acerada de los tiempos modernos.

Para el gran pensador la sociedad, desviada del cauce que le fijan sus fines naturales, está condenada al dolor y a la miseria. EI hombre es originariamente bueno; pero la sociedad actual lo ha deformado. En este punto, las ideas de Tolstoy se confunden con las de Rousseau. Pero difieren en que, mientras para Rousseau, hay una antinomia irreductible entre naturaleza y sociedad, para Tolstoy la sociedad es una continuación de la naturaleza. Según Rousseau, el hombre, salido del estado de naturaleza, ha perdido/definitivamente su felicidad, porque no puede ya volver a ella. Una cosa sola le es posible: transigir con la sociedad, adaptarse a ella abandonando sus mejores esperanzas a la consecución de la felicidad a la que tiene derecho por su origen. A Tolstoy no le abandonó jamás su fe en la regeneración humana. Por una desviación inconcebible, el hombre se ha alejado de la naturaleza. Mientras en la naiuraleza todo esverdad, todo es bien, todo es belleza la sociedad moderna está fundada sobre la mentira, la hipocresía, la

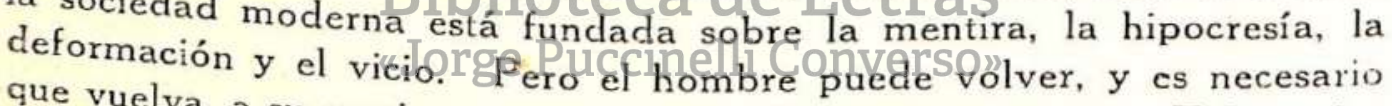
que vuelva, a su camino recto. A esta obra quiso consagrar Tolstoy las mejores actividades de su vida. Ante el espectáculo de ía corzupción general, el escritor ruso se
siente extranjero a todos los partidos y todas las patrias. Como Dante
en el destierro ideal restierro, se propuso formar él solo un partido contra todos. Su lo lanzaron a demoledor y la lógica inflexible de su doctrina y optó por lo primilema: "separarse de los hombres o de la verdad", que dice: " primero, adoptando como lema el antiguo proverbio ruso

En consecuejo que miente es un rico que roba".

sas, políticas y literia, combate todas las supercherías sociales, religiodoxa, a la autorias, todos los fetiches reinantes: a la iglesia ortoJismo, a la ciencia, a zarista, a la nobleza, a las instituciones, al liberatalla en todos los, a la administración de justicia. Tolstoy da la bala vez más general frentes de la actividad rusa para que su acción sea a Pero lo gueral e intensa.

ras, sino las nuevas: nuncia con más energía no son las antiguas mentino es la organización feudal, es la mentira de la democracia; no es la. 
opresión de las clases privilegiadas, es la mentira de los falsos amigos del pueblo.

Esta mentira se traduce en una constante contradicción, visible en todos los órdenes de la vida social. Cada uno sabe que todos los hombres tienen los mismos derechos, que todos los hombres son iguales; y sin embargo, cada uno ve en torno suyo la división de los hombres en dos castas, la una miserable y oprimida, que se consume en el trabajo y en el sufrimiento, la otra ociosa, dominante, feliz, que vive en lujo y la disipación. Aun más, todos tienen conciencia de este mal, y lo condenan; y no obstante, todos, de un lado o de otral contribuyen voluntariamente o no a su mantenimiento. "Amo o esclavo, el hombre moderno no puede dejar de sentir la contradicción constante entre su conciencia y la realidad, ni desconocer los sufrimientos que resultan de ella".

Esta contradicción hace la esclavitud moderna, mil veces más oprebiosa o irritante que la antigua. Toda la libertad de hoy no es sino la esclavitud envuelta en un ropaje dorado. La esclavitud antigua xeposaba sobre el consentimiento de los esclavos. La aceptaban como una necesidad natural. Se resignaban a ella como a una fatalidad contra la que era no sólo inútil sino ilícito rebelarse. El obrero de hoy se siente esclavo, y sabe que no debia serlo. Y esta conciencia no solamente acrecienta su sufrimiento, sino que es la causa principal de su desgracia.

La misma contradicción hace la miseria de las clases cultas. Los hombres de esta categoría están penetrados de los sentimientos de humanidad y de justicia, y bre principios diametralmenteciopulestoson Saben "que todos son hermanos, y la misión que les da la sociedad es la de juzgar, condenar, encarcelar y matar a los otros hombres. Saben que todos son hermanos, y deben perseguir a los que no pueden pagar, o fabricar instrumentos para sembrar la desolación en los unos o reducir a la impotencia a los otros.

La vida política está llena de las mismas contradicciones. El liberalismo, la democracia, el constitucionalismo, son otras tantas mentiras importadas del Occidente. El pueblo no sólo no ha ganado, sino que ha empeorado su situación con el cambio de la antigua administración conservadora por la administración liberal. No ha ganado con ella sino un mentira más, mentira que no tiene la excusa de la tradición o de la consagración de los siglos. Tolstoy se indigna del abuso que los liberales hacen de las palabras pueblo, voluntad popular, soberanía. La democracia es una nueva superchería, superchería que ha servido para hundir más al pueblo en la abyección. Con el complejo sistema de las elecciones se le ha hecho creer que elige directamente sus representan. tes, que participa en el gobierno de la nación, y que, obedeciéndolo, obedecen a su propia voluntad. Pero el pueblo no puede expresar su 
voluntad por el sufragio: $1 \circ$ - porque la voluntad colectiva de una nación de varios millones de habitantes no puede existir; $2^{\circ}$-porque aun existiendo, no podría expresarse, descle que el sufragio es y ha sido siempre una mistificación; $3^{\circ}$ - porque aunque fuera honrada y legal, la expresión de la mayoría no sería la expresión de la nación. Por otra parte la democracia es funesta: 10-porque la mayoría es siempre la masa ignorante de la población; $2^{n-}$-porque los gobernantes elegidos administran no en vista del bien general, sino en el suyo propio y para mantenerse en el poder. "Esos hombres liberales, dice Tolstoy, me recuerdan a aquellos presos que se imaginan gozar de la libertad, porque tienen el derecho de elegir entre sus carceleros a los encargados de la policía interior de la prisión". Y agrega: "El súbdito de un Estado despótico puede ser enteramente libre, aun dentro de las más crueles violencias; pero el miembro de un Estado constitucional es siempre esclavo, pues reconoce la legalidad de las violencias cometidas contra él. Y he ahí cómo se quiere conducir al pueblo ruso al mismo estado de esclavitud constitucional en que se encuentran los otros pueblos europeos".

El liberalismo tiene como aliado al cientifismo. La ciencia es otra de las supercherías modernas. A sus problemas, origen de las especies, análisis espectral, teoría de los púmeros, animales fósiles, se les atribuye la misma importancia que en la edad media a los universales, la dualidad de la sustancia, la astrología o la piedra filosofal. Los sabios son los sirvientes de la inteligencia, que, como los sirvientes de la Iglesia, se persuaden y persuaden abỏs demás de dque salvan a da humanidad, que creen y hacen creer, como la Iglesia también, en su infalibilidad, que no están de acuerdo jamás, quée se dividen en capillás, 'y " que en vez de producir el saber, son la causa de la oscuridad y de la ignorancia, del retardo que sufre el hombre en libertarse del mal; pues ellos han rechazado la única cosa que puede unir a los hombres: la unidad de la conciencia humana.

La raíz de estos males hay que buscarlos en gran parte en la educación moderna, cuyo efecto más inmediato es la crisis del matrimonio. Según Tolstoy, el fin de la educación en nuestros tiempos es el placer. gos hombres son educados en la escuela del libertinaje; libertinaje organizado por los padres, consentido y reglamentado por el Estado, estibarde e por la falsa ciencia. Los padres lanzan a los hijos al goce coel Estado moviliza ; la ciencia sostiene que es necesario para la salud; los ciudadanos. cierto. Y lo que es bien, dice Tolstoy, lo que afirma la ciencia no es afirma. Su opinión estás grave, esa ciencia sabe que no es verdad lo que saria para sustentar un exmentida por la sana experiencia. Pero es necero suponiendo que fuera verdalado del orden social que sirve. $\mathrm{Pe}$ ría inexcusable. No puederdad lo que la ciencia afirma, así y todo se- 
sea preciso perder la salud de los otros. Tanto valdría sostener que para enriquecer nuestra sangre nos fuera lícito beber la sangre de los demás. Es la crisis de la educación, porque se enseña a los jóvenes que la moral puede rasgarse como un pedazo de papel cuando está de por medio un placer o una necesidad, y porque esas relaciones son legales e implican un comercio infame y cobarde, infame porque es a base de dinero, y cobarde porque el hombre se exime de las consecuencias y arroja sobre la parte más débil toda la responsabilidad en una desigualdad monstruosa.

En la educación de la mujer pasa lo mismo. Las mujeres son educadas para el placer en vista del matrimonio. Como los príncipes son educados para reinar, ellas son educadas para casarse; y por esa educación saben que el desideratum de su suerte está en las prendas físicas. Por eso desde la más tierna infancia se consagran a ellas con ardor. Saben que es su cuerpo y no su alma lo que decidirá su destino, y obran en consecuencia. Pueden dividirse en rangos, categorías, esferas sociales, pero en cuanto a los medios puestos en práctica para abrirse camino en la vida, no hay diferencia. Todas ponen en juego los mismos recursos. En el vestir, en los modales, en las maneras, en las armas que usan, todas son iguales. Todas son cortesanas. Unas lo son a corto plazo por eso son menospreciadas, las otras lo son a largo plazo por eso son estimadas. Es la esclavitud de la mujer; esclavitud bajo apariencia de dominación. Las mujeres dominan con su esclavitud como los judíos. ¿Queréis, dicen los judíos, que no seamos sino mercaderes? Pues bien, seremos' ${ }^{\circ}$ mercaderes; perog coma-merçaderes os dominaremos. Y como mercaderes han dominado. ¿Queréis, parecen decir las mujeres, que no seamros sinb Gbjetos de placerș 0 Pues bien, como objetos de placer os dominaremos. $\mathrm{Y}$ como objetos de placer han dominado.

Y es que la desigualdad de la mujer no está en la privación del sufragio y de la magistratura. Está en el bajo nivel moral en que se la coloca. En el hecho de ser un medio, en tanto que el hombre se reserva hipócritamente la condición de fin. Su verdadera dignificación comenzará en el momento en que sea considerada como un fin en sí y no como un simple medio de satisfacción para el hombre. Mientras sus relaciones con el hombre estén basadas en la sensualidad, la mujer será una esclava. La mujer necesita elegir su destino, sus relaciones, su vida, independientemente de toda otra consideración que no sea el valor de su personalidad moral.

El único medio de conjurar esta corrupción social que todo lo envenenaba era la Revolución. Pero la Revolución de Tolstoy tenía una envergadura distinta de la que planeaban los revolucionarios, militantes: una Revolución que deponía las armas y apelaba al amor: la Revolución predicada por Cristo, que en veinte siglos no ha cesado de llamar a los hombres al reino de Dios. 
Tolstoy eleva el arte a la categoría de una religión social. El arte es, según él, un instrumento de comunicación entre los hombres. No puede concebirse como una manifestación de lo bello, es decir del placer. Es más que eso: una condición de la vida, una actividad por la que el hombre expresa conscientemente sus sentimientos en virtud de ciertos signos exteriores, sentimientos que al propagarse y revivirse por los otros crean ondas de vasta solidaridad humana. El arte, por eso debe llenar un requisito esencial: el ser inteligible, es decir, debe impresionar y trasmitir las sensaciones, cualesquiera que ellas sean, verdaderas o falsas, con tal que sean capaces de aquella resonancia interior que las hace fecundas e inmortales. Si no puede trasmitirlas o si al crearlas caen en el vacío, es porque carecen de vida, que es lo único que hace digno y grande al arte. Cuando sin ningún esfuerzo de nuestra parte, en presencia de la obra de otro hombre, recibimos una emoción que nos une a ese hombre y a otros hombres, es que la obra ante la cual nos encontramos es una obra de arte. No lo será, en cambio, aun adornada con los más ricos efectos, aquella que no despierta en nosotros el gozo de sentirnos en comunicación con el autor y cen los otros hombres. "E. arte bueno, grande, universal, puede ser incomprensible para un círculo limitado de gentes corrompidas, pero no para la gran mayoría de los hombres simples". En vez de pretender iniciar a la mayoría de las gentes sencillas en el arte difícil, el verdadero artista debe procurar que su arte esté en condición de llegara ellas sin esfuerzo alguno, por el solo hecho de ser natural y humano. Debe, por lo tanto, reflejar, de un lado, la naturaleza, y de plyolo grechayde mástgeperal y profundo en el corazón de los hombres. Decir de una obra de arte que es buena, y pretencier al mismo "tiempo que fio está hecha para todo el mundo, es lo mismo que decir que un alimento es excelente, pero que los hombies no pueden comerlo".

¿Qué es el arté? de Tolstoy, es la requisitoria más violenta contra el arte moderno. Según el escritor ruso, se han asignado al arte los fines más extraños y que menos le convienen por su naturaleza y su esencia. Para Tolstoy, el fin legítimo del arte es un fil útil: el bien. Por tistas quier del arte por el arte, máscara con que la mayoría de los artistas quiere encubrir su monstruoso egoísmo. Es aque!la una casta del tado, Ejército, qués de destruír las otras castas dicm nantes. Iglesia, Espojos. "No quiere instalarse en su lugar y enriquecerse con sus desvendedores del temple, dice, pero en su nombre quiero arrojar a los agua. No es un ado". El arte es tan necesario ccmo el pan y el tienen una misión adorno ni un lujo, siro un apostolado. Los artistas ningún derecho y se cumplir, y sólo la cumplen cuando no se arrogan cia de esta jamás esta misión es la abnegación y el sacrificio. El artista no deberá jamás permanecer en las alturas olímpicas, sino en la inquietud y en la emoción. Un artista ponderado y sereno es tan absurdo como un Dios 
que permaneciera indiferente ante el dolor de las criaturas. Tal fué el error de Goethe y de todos los que han hecho del arte un refugio de su propio goísmo.

La pasión con que defendió sus ideas lo hizo incurrir a veces en graves injusticias y atacar a hombres como Shakespeare, Ibsen, Wagner, Beethoven, Straus, en quienes debió reconocer su mismo espíritu.

En resumen cंqué es lo que constituye el arte verdadero? El arte verdadero es el accesible a todo el mundo, el arte que sirve de órgano moral de la vida humana, de medio de perfeccionamiento moral de los hombres, que ayuda a realizar en el mundo la unión y la felicidad, que traduce la conciencia religiosa de la humanidad, es decir la aspiración al bien por la fraternidad y el amor. Muy pocos son los autores y las obras en que Tolstoy encuentra los signos del verdadero arte: Dikens, Destoievski, Víctor Hugo en Los Miserables, Cervantes en el Quijote, Moliére, las leyendas, los cuentos y las canciones populares, y sobre todo el Génesis y los Evangelios.

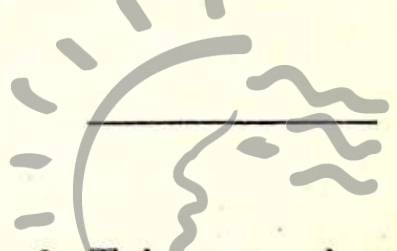

En la novela es donde Tolstoy revela mejor la universalidad de su genio, universalidad que le permitió poner al servicio de su arte la profundidad cle su pensamiento y su aptitud para el análisis ejercitada en su requisitoria social. En su noyela se funden, pues, intimamente, el filósofo y el artista, y esta fusión intima da a su obra una fisonomía original y única. El"nervio delfa novela tolstbianás el pensamiento; pero la fina sensibilidad artística del escritor le da esa seducción encantadora que es uno de sus méritos principales.

Hay que reconocer ante todo dos cualidades en este gran novelista: su imaginación viva y exuberante y su prodigioso poder de evocación. Cuando Tolstoy nos presenta un objeto, lo vemos por todos sus contornos, en todas sus líneas y en sus más insignificantes detalles. Pero no pinta por describir. Tiende a dar la impresión del objeto, a interpretarlo, y para esto busca y afirma el rasgo que traduce mejor su vida y su fuerza interior. Lo mismo hace con los sucesos: agolpa los hechos a nuestra vista, y nos da la sensación más viva y real de la acción. Pero tampoco narra por narrar. Persigue a través del acontecimiento el instante que traduce más fielmente el alma del proceso, el impulso que lo mueve y agita. Porque para Tolstoy los acontecimientos están animados por un espíritu, que es la ley que preside su desenvolvimiento.

En los personajes seduce su prodigioso relieve; los vé íntegramente $y$ en todos sus aspectos, en su apariencia externa y en la intimidad de su vida interior. Pero no es sólo esto. No permanece en la actitud de 
mero observador, sino que interviene en su mundo; se coloca entre ellos; siente y piensa con ellos; sufre con sus dolores, goza con sus alegrías; participa de sus inquietudes, de sus sueños, de sus esperanzas. Por esc pudo decir que "no darse todo entero en su obra le parecía tan imposible como llorar con otra cosa que no fueran los propios ojos ni pensar con otra cosa que no fuera el propio cerebro".

Pero lo que ha hecho de Tolstoy el gran reformador de la novela es su concepción de la acción. La acción de la novela tolstoiana se distingue por su espontaneidad animada y viviente. Su desarrollo es tumultuoso y complicado, y carece de toda lógica convencional. Por lo general, no existe en ella una rigurosa unidad, ni un solo drama ni una sola novela, sino muchos dramas y muchas novelas, unidas, como en la vida, por lazos contingentes. A primera vista se nota la ausencia absoluta de composición. El autor se deja conducir naturalmente por los acontecimientos que narra sin sentirse jamás constreñido por un plan trazado de antemano. Es que en la novela de Tolstoy el genio desborda el arte. Sus obras dan la impresión de la arquitectura, donde una parte, destacada del todo, no explica por si misma su razón de ser, o parece de exageradas dimensiones: pero que en el conjunto contribuye a la armonía general. Por eso lo que se admira en Tolstoy no es tal o cual parte de su obra, sino la obra total, gigante y desproporcionada.

Guerra y $\mathrm{Paz}$ es la epopeya rusa de la invasión napoleónica, la más grande epopeya de los tiempos modernos. Un mundo se agita en ella, con sus ideales, susigandezes Gasus misectasl asobre este mundo, el novelista enfoca su yjsión tumultuosa.] frácicica dastêsca de la vida.

El mundo de Guerra y Paz está gobernado y dirigido por el Destino. Su fatalidad inexorable planea magestuosamente sobre los hombres. Al principio en calma, un fondo cenagoso cubre un acervo de pasiones y vicios largo tiempo acumulados. Pero estalla la tempestad, y emergen a la superficie sombras que son almas muertas bajo cuerpos esclavos. El príncipe Basilio traduce en una frase el pensamiento de Tolstoy sobre la corrupción rusa: "Pecamos y engañamos. Es la muerte, la muerte de una vida que comienza y termina con la muerte".

$\mathrm{El}$ ejército ruso está en Austerlitz, y el encuentro con Napoleón es inminente. Los soldados se alistan para el combate; los generales conciben sus planes de batalla. Pero en medio de la agitación que convulsiona a los hombres y hace trepidar los campos, se siente la inutilidad de todo esfuerzo; porque el Destino, que gobierna los acontecimientos, ha dictado ya su sentencia, y todo está determinado de antemano. Kutuzof, el generalísimo ruso, duerme en el consejo que discute el plan de batalla. La acción señala un día de duelo para Rusia. No importa: Kutuzof sabe que era la voluntad de Dios.

Después de un corto período de calma, el mar vuelve a agitarse. La tempestad estalla con más fuerza. Los hombres se lanzan contra los hombres y las pasiones contra las pasiones. Napoleón ha invadido a 
Rusia. Es la batalla de Borodino. El generalísimo Kutuzof muestra la misma negligencia de Austerlitz: la víspera de la batalla lee una novela. Tampoco importa. El Destino vela por él. Borodino es una gloriosa jornada para Rusia, y Kutuzof, el Héroe. En el generalísimo encarna Tolstoy el alma rusa y su sumisión al Destino.

Los personajes están divididos en dos órdenes: uno el de los elegidos, otro el de los réprobos. Los elegidos son los simples, los humildes. los que se someten resignadamente a la voluntad de Dios: Kutuzof, Besukof, la princesa María. Los segundos son los rebeldes, los que se empeñan en forzar la fatalidad del Destino: Napoleón, el príncipe Andrés, el príncipe Bolkonski.

Pero en realidad el verdadero héroe de Guerra y $\mathrm{Paz}$ es el pueblo: ejército, nobleza, clases dirigentes, gobernantes; con sus inquietudes. sus esperanzas, sus desfallecimientos, sus crisis morales, sus sufrimientos físicos, sus miserias. Y tras el pueblo, como los dioses tras los héroes de Homero, la Fatalidad, presente en todos los momentos, dirige la ruta de los hombres y de las naciones. Pero las contiendas de estas multitudes, épicas y gigantescas, tienen una grandeza apocalíptica.

Dos personajes se reparten la personalidad de Tolstoy: el príncipe Andrés y Pedro Besukof. El príncipe Andrés parece primero sumido en la vida desorbitada de la juventud elegante, después en vías de regeneración partiendo para la guerra y asistiendo a la batalla de Austerlitz. Su reforma no es, sjn embargo, profunda, porque su ideal está tocado de soberbia y orgullo. Ilofascinąlagenio de Napbléón, y quiere emularlo. Una bala lo alcanżoygaè Eudextendidoodecespaldas, ve solamente, sobre él, muy alto, un cielo infinito, profundo, sereno, donde vagan muellemente ligeras nubes grises. No creía haberlo visto nunca. Por lo menos no había advertido jamás la serenidad de ese azul transparente que llenaba su espíritu de paz. “QQué calma! —exclama- łqué paz!. ¡qué diferencia con mi carrera desenfrenada! ¡Cómo no había advertido antes este alto cielo? ¿Qué feliz soy de haberlo encontrado al fin! Sí, todo es vacío, todo es vanidad, excepto él. No hay nada fuera de él. ¡Loado sea Dios!" Sin embargo, la vida lo recobra, y la ola de! mundo lo arroja otra vez a la desgracia y a la miseria. En ocasiones, una racha de viento puro lo acaricia. Se acerca a la encantadora Natacha. Después ella es arrojada a los brazos del primer seductor que pasa, y el príncipe Andrés cae nuevamente en el vacío.

Pedro Besukof es un espíritu recto, pero ondulante y vario. Sabe que una misión altísima lo llama; sabe que es hacia los desdichados que debe ir; pero no acierta con la ruta, y en los innumerables tanteos de la acción se pierde estérilmente su vida.

Pero lo que hace el encanto de esta obra es su galería de muchachas: Sonia, María, Natacha, las más dulces y tiernas creaciones de Tolstoy y en las que el escritor acumuló toda la poesía que le dejaron 
sus mejores recuerdos de la juventud. Todas ellas seducen por su gracia infantil, su abandono inconsciente a la alegría de vivir,- la fragilidad vaporosa de sus sueños, su riente despreocupación en medio de la desgracia que las envuelve. Natacha, sobre todo, es una figura inolvidable. Se le ve crecer; se le sigue paso a paso en la vida, desde sus primeras emociones hasta que su corazón se abre al amor del príncipe Andrés; desde la noche en que acodada al balcón de su ventana habla locamente enamorada del príncipe que la escucha, hasta aquella otra noche lúgubre en que vela al amado, herido en la batalla de Austerlitz.

A Guerra y Paz siguió Ana Karenin. En esta obra, el diafragma de la visión tolstoiana se reduce y estrecha, pero alcanza más concentración. Pierde en amplitud lo que gana en profundidad. También es aquí la fatalidad el resorte de la acción, que se muestra ya no en el curso ciego de los acontecimientos, sino en el torrente incontenible de un amor que precipita a los protagonistas a la catástrofe. El amor que debió conducir a Ana a un orden de paz y de perfeccionamiento moral, dentro de la corrupción social en que yive, hace por el contrario su desgracia. Ana se había casado $\sin$ amor obedeciendo a una exigencia social. Jamás amó a su esposo. Todo concurría en ella para hacerla feliz. Pertenecía a la mejor sociedad. Bella,graciosa, elegante, inteligente, de expresión dulce y acariciadora, poseía todos los encantos y todas las virtudes. "Cuando se le encontraba por primera vez, era imposible dejar de volver la cara para mirarla nuevamente. Sus ojos grises, que unas espesas pestañas hacían parecer oscuros, concentraban una mirada amigable y benévola. Habia en su fisonomía una vivacidad contenida, que se labriapasoCentre Pa mediásonrisa de dos labios

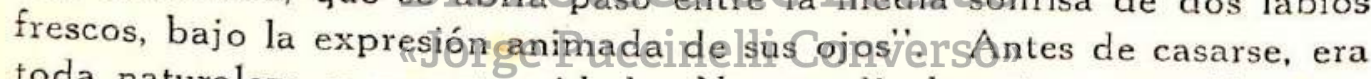
toda naturaleza y espontaneidad. No sucedía lo mismo con Karenin, que era el más perfecto producto social. Era un hombre de Estado, seco, frío, ordenado y metódico, que no tenía sino un solo culto: la opinión pública; y una sola ley: las conveniencias sociales. Consideraba peligrosos todos los sentimientos y vivía encerrado dentro de las formas frías de una cortesía artificial. Un día el amor de Vronski abre los ojos a Ana. Hasta entonces había vivido ciega. Las cosas más familiares se le aparecían ahora bajo nuevas formas y bajo nuevos aspectos. Al ver nuevamente a su esposo en la estación de Petersburgo, descubre en él rasgos absurdos que antes no había advertido. Su mismo hijo está cambiado. Lucha contra este amor, pero es en vano; y cuando se entrega a él, el marido sólo piensa en salvar las apariencias: lo único que busca es una mentira para satisfacer a la opinión pública y evitar el escándalo. Ana no puede resistir esta atmósfera de disimulo, y parte con Vronski. Pronto advierte que ya no podía recobrar lo que la sociedad le había quitado. Los daños que infiere la sociedad son irreparables. En el campo, sola con Vronski, tiene también que mentir. Sus angustias alteran el equilibrio de sus nervios, y aparecen los celos, y con los 
celos la desesperación. Para lograr una paz que ya no puede esperar de la vida, Ana se arroja bajo las ruedas de un tren en marcha.

La influencia de Rousseau en Ana Karenin es evidente. Entre esta obra y La Nueva Eloisa hay puntos de contacto que no pueden pasar inadvertidos. Ana y Julia son víctimas del medio social en que viven; ambas expían inocentemente las preocupaciones que las envuelven desde la cuna; en ambas la sociedad y sus prejuicios se oponen al amor a que tienen derecho. Pero Rousseau y Tolstoy resuelven de distinta manera el conflicto que en la pasión de sus heroínas crea la oposición entre la naturaleza y la sociedad. Para Rousseau, la sociedad es ya un hecho real e inevitable, cuyo origen está en el instinto de perfectibilidad que poseemos, casi una segunda naturaleza de la que los hombres no pueden salir una vez que han ingresado en ella. $Y$ he aquí el dilema que plantea la pasión cuando entran en juego la sociedad y la naiuraleza: o rebelarse contra la sociedad, que entonces arrolla y aplasta a su víctima; o transigir con un mal del que es imposible sustraerse, sacrificándole la felicidad para recibir en recompensa la paz de una existencia vacía y mediocre. Julia y Saint Preux eligen el primer camino, de acuerdo con la filosofía práctica de Rousseau: renuncian a su amor y destrozan su vida. Para Tolstoy, la antinomia es irreductible en el estado actual de los hombres; porque aunque la sociedad es una continuación de la naturaleza, ella se encuentra hoy depravada y corrompida por la mentira, la hipocresía y el vicio; y el dolor y la miseria son efectos naturales y lógicos del malestar de la época. Ana y Vronski, lanzados por la violenoiade sutarnor, que losobstaculos sociales convierten en un torrente ingontenible marcharon rápida y fatalmente a la catástrofe.

Ana nos recuerda también a Mme. Bobary. A una y otra el vacío de su vida las llevó a la desgracia. El primer amante les da a ambas la conciencia exacta de este vacío que antes no habían advertido. Al regresar de Pertersburgo, lo primero que ve Ana en la estación es a su marido: “¿Dios mío! ¿Por qué se le han alargado tanto las orejas?” piensa al contemplar la fisonomía fría pero distinguida de Karenin. Y un sentimiento penoso empieza a torturar su espíritu. El primer amante revela a Emma la pobreza intelectual de Carlos Bobary y la prosa de su vida burguesa. La tragedia en ambas es la misma; pero su situación es diferente. Mme. Bobary es una mujer sensual y romántica a quien pierde el ideal de una vida imposible, extraña a su origen, a su medio y a sus condiciones. Su drama es la loca aventura del que pretende ser lo que no se es y no se puede ser. En la persecución de este ideal inaccesible, la desdichada Emma cae en brazos de sucesivos amantes. Ana Karenin es, por el contrario, leal, sincera, generosa, la pierde el deseo de rehacer su vida y tomar de ella aquello a que creía tener derecho. Mme. Bobary expía en su catástrofe el error de su educación sentimental. Ana 
es la víctima inocente de una sociedad organizada sobre absurdas preocupaciones.

Karenin es una de las mejores creaciones de Tolstoy, es el tipo acabado del gran funcionamiento, el hombre público distinguido y mediocre, en el que todos los gestos y ademanes son estudiados, que esconde constantemente tras una sonrisa finamente irónica su pobreza intelectual y sabe discernir a cada uno la mentira que más le halaga; modelo de virtud farisea y dignidad mundana, subordina la vida a la norma y el sentimiento a las conveniencias sociales.

Levín vale por su carácter autobiográfico. Este personaje es el mismo Tolstoy con las dudas, inquietudes e ideas del tiempos en que escribió la novela. Todo el amargo proceso de su crisis moral revive en él. La angustiada pregunta que se hace Levín: "¿Hay razón para vivir como yo lo hago?" es la expresión exacta del estado de ánimo del gran escritor. ¿"Qué soy?-dice Tolstoy en su Confesión- ¿Por qué vivo? ¿Cuál es el fin de mi vida? ¿Cómo debo vivir? ¿Dónde está el bien? ¿Dónde el mal? Seré rico, célebre, etc., y después...? ¿Qué saldrá de lo que hago hoy, de lo que haré mañana? ¿Qué saldrá de toda mi vida? ¿Por qué debo hatceralgo? ¿Hay en la vida un fin que no se destruye con la muerte inevitable que me espera?"

La obra tiene también un interés crítico. Ana Karenin es una valiente requisitoria contra la corrupción de la sociedad contemporánea En ella denuncia todas las mentiras, las que crecen a la sombra de la virtud y las que se arrastran en el fango del vicio, la religión elegante de los salones y la falsab caridad de los hipócritas las mistificaciones liberales y los sofismas democráticos. En medio de esta mentira general, una sola cosa es werdad, und sola cosatiranea la careta a los hombres y hace ver hasta el fondo las conciencias: la muerte.

En La Muexte de Iván Illicht, Tolstoy prosigue su requisitoria sobre la mentira social; pero aquí la circunscribe a la burguesía de su tiempo, la burguesía positivista que lee a Zolá y admira a Spéncer, que no tiene otra preocupación que el bienestar material. El protagon sta es un Karenin de rasgos más pronunciados, cuya vida vacía, rutinaria y mediocre es una mentira desde la cuna hasta la tumba, con sus ambiciones grotescas, sus pobres satisfacciones de amor propio, sus aspiraciones mezquinas, deslizándose en una monotonía desesperante. Iván Illicht es el tipo de esos funcionarios meticulosos, huérfanos de pensamiento e iniciativa y acometidos de incurable pereza mental, que se absorben en sus funciones hasta la hora de la muerte, en que advierten que no han vivido. Y esta vida vulgar y ridícula se pierde por una causa más vulgar y ridícula todavía. Iván Illicht cae de una escalera al arreglar una cortina de su casa. Mentira de la enfermedad, que se oculta; mentira del médico, que cura mentiras; mentira de la familia, a la cual molesta la enfermedad; mentira de la esposa, que afecta consagración y sólo piensa en la forma en que ha de vivir cuando el marido muera. Mentira uni- 
versal, a la cual se opone una sola verdad, como en Ana Karenin: la de la muerte.

En la Sonaka a Kreutzer, Tolstoy dirige su crítica contra el matrimonio y denuncia su degeneración. Por su forma es una información, un alegato. Posnichof hace a un extraño la confidencia de su tragedia. Fué desgraciado desde el día de su matrimonio, Educados para el placer, él y su esposa, y agotado el placer efímero que buscaron en él, cada uno se convirtió en obstáculo para el otro en la persecución de nuevos placeres. Posnichof no mata por celos, desde que no amaba a su mujer: mata por odio; el odio acumulado durante varios años de sinsabores. El proceso de Posnichof'es semejante al de Otelo. Pero Otelo amaba apasionadamente a Desdémona, y obra acosado por unos celos que fatales apariencias alimentaban. En Posnichof ni el más leve motivo de infidelidad, real o aparente, podía explicar su conducta. Había caído en el delirio horrible de una locura salvaje y rodaba precipitadamente a su catástrofe sin siquiera saberlo. En la Sonata a Kreutzer, por la pintura de este desequilibrado a quien tortura la exaltación mórbida de su memoria, Tolstoy alcanza las cimas de Dostoievski.

Resurrección es el último mensaje del gran escritor a la humanidad, su testamento artístico, el eyángelio de su redentorismo cristiano. La figura de Tolstoy en esta obra alcanza sus perfiles definitivos. En ella aparece revestido de una serenidad religiosa y apostólica, que es la serenidad con que ha de verle y admirarle la posteridad. Parece mirar de lo alto y por encima de las cosas, lejos de la contienda de los hombres y de las pasiones. Podría decirse que es un Goethe cristiano. La sombría ironía, èloataqueeviodente la sátira implacable han desaparecido.

La idea esencial de la obra es la necesidad" de la reparación. No es suficiente el arrepentimiento, ni el remordimiento, ni la oración. Esos son los recursos fariseos, la careta piadosa con que se cubre el egoísrno. Debemos reparar el mal con nuestra felicidad y nuestra vida.

El descenso paulatino por todos los grados de la abyección de una niña pura e inocente, lanzada a la ignominia por el egoísmo brutal de un hombre y abandonada luego a la voracidad de todos los apetitos, le da margen para pintar los vicios y crímenes de la sociedad moderna, las injusticias de la justicia, los escándalos de la administración carcelaria. Katiucha era la hija de una pastora, recogida por dos tías a pasar cuatro días de vacaciones. La víspera de marcharse la seduce. Katiucha tiene que dejar la casa y abandonar a su hijo, siendo en todas partes objeto de las asiduidades más repugnantes. Encontrándose sin recursos, acepta la proposición de una casa de tolerancia. De un lado tenía la humillación tenebrosa, de otro la situación asegurada y tranquila, lucrativa, bajo la protección de la ley. Katiucha se decidió por el segundo partido. Desde ese momento va descendiendo escalón por escalón en la abyección más repugnante. Katiucha cede el paso a la 
Maslova, nombre que adopta en su nuevo oficio. Acusada injustamente de haber asesinado a uno de sus clientes, es llevada ante los tribunales. Nekloudof está entre los jurados y reconoce a la pupila de sus tías. Por un error del jurado, y debido especialmente a la precipitación del presidente que tenía una cita con su querida, Maslova, perfectamente inocente, es condenada a trabajos forzados en Siberia. Nekloudof resuelve reparar su falta casándose con ella. Pero la Maslova está embrutecida por el vicio y el alcohol. El príncipe logra con sus influencias que haga el viaje con los presos políticos. El contacto con los nihilistas, gente pura que vive fuera de la sociedad, la regenera. En Siberia, Katiucha agradece al príncipe su ofrecimiento, pero le avisa que prefiere casarse con Simonson, el nihilista que Tolstoy hubiera querido ser. Casándose con Simonson, Katiucha haría un doble bien: impediría el sacrificio de Nekloudof y realizaría la felicidad de Simonson.

Al contemplar Tolstoy la pureza de vida de los revolucionarios y la elevación de sus ideales, exclama por boca de Nekloudof: "La cárcel es hoy en Rusia el único rincón seguro para un hombre honrado".

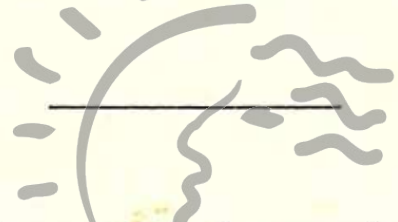

Dos caracteres pueden resumir la grandeza de la obra tolstoiana. Ella es el cuadro más sombrío y trágico de la miseria humana, de un lado; y de otro, el himno más generoso al amor fraternal de los hombres. Pero lo que eleva a Tolstoy a da alturat de los grandes reformadores es la conciencia profunda que tuvo de nuestra miseria y la claridad con que supo mirar en su fondo. Er el fornc? "de la miseria humana encontró Tolstoy la tendencia a la aprehensión de los bienes materiales. Para conservarlos el hombre necesita las armas, la mentira, el fraude y la perfidia. Sólo en el renunciamiento, en la absoluta dejación de esos bienes, el hombre puede encontrar la salud. Esta doctrina predicada no sólo con su palabra sino también con su ejemplo, lo acercan a Cristo, a Buda y a Francisco de Asís.

Pero esta conciencia hizo también la tragedia de su vida. Convencido de la necesidad en que estaba de abandonar sus bienes, no pudo, sin embargo, hacer su voluntad, por la tenaz oposición de los suyos. Por esto, Tolstoy se nos ofrece como la expresión más alta de nuestra grandeza y de nuestra miseria. De nuestra grandeza, por la elevación enorme de sus ideales; de nuestra miseria, por su impotencia para darles realidad en la vida. 